\title{
Residual entropy in the zero-temperature limit of toluene glass
}

\author{
M. Moratalla ${ }^{1}$, P. Bejarano ${ }^{1}$, J.M. Castilla ${ }^{1}$, and M.A. Ramos ${ }^{1,2}$ \\ ${ }^{1}$ Laboratorio de Bajas Temperaturas, Departamento de Física de la Materia Condensada \\ Universidad Autónoma de Madrid, Madrid, Spain \\ ${ }^{2}$ Condensed Matter Physics Center (IFIMAC) and Instituto Nicolás Cabrera (INC) \\ Universidad Autónoma de Madrid, Madrid, Spain \\ E-mail: miguel.ramos@uam.es
}

Received October 24, 2018

\begin{abstract}
The specific heat $C_{p}$ of toluene, doped with $2 \mathrm{~mol} \%$ ethanol to avoid rapid crystallization, has been measured in both glass and crystal states, and with special accuracy at low temperatures in the range $1.8-20 \mathrm{~K}$ using the thermal relaxation method. By making use of the complementary $C_{p}$ curves measured in the reference crystal state, we have been able to obtain the entropy curve of the glass and eventually the residual entropy of toluene glass in the zero-temperature limit, that is found to be $5.1 \mathrm{~J} /(\mathrm{K} \cdot \mathrm{mol})$. This value is clearly lower than others previously reported in the literature, which lack the knowledge of the particular specific-heat behavior of glasses at low temperatures and hence overestimated the glass residual entropy at zero temperature. In addition, we have studied in detail such low-temperature "glassy anomalies" in the case of toluene, extending and improving previous measurements. The surprising depletion previously reported of tunneling two-level systems in toluene glass has been confirmed, though this fact coexists with the presence of a broad peak typical of glasses (the socalled boson peak) in $C_{p} / T^{3}$ at $4.5 \mathrm{~K}$. For the toluene crystal, the expected cubic Debye behavior has been found at lower temperatures.
\end{abstract}

Keywords: specific heat, glass transition, toluene, entropy of glasses, tunneling states, boson peak.

\section{Introduction}

As P.W. Anderson stated at the end of last century, "The deepest and most interesting unsolved problem in solid state theory is probably the theory of the nature of the glass and the glass transition" [1]. To shed light on this matter, we aim at investigating the interrelation between the glass transition phenomenon and the "anomalous" physical properties of glasses at low temperatures. As a benchmark, we will study toluene in both glass and crystal states.

\subsection{The glass transition}

As is well known, when a liquid is cooled two different paths to the solid state can be followed, in principle: either the liquid experiences an abrupt, first-order transition below its melting temperature into a crystalline state, or the liquid can be supercooled continuously, while rapidly increasing its viscosity and hence the averaged molecular relaxation time, until at a certain temperature $T_{g}$ (the glass transition temperature) the substance deviates from the liquid thermodynamic equilibrium curve and becomes a glass, i.e., a non-crystalline solid [2-9].

(c) M. Moratalla, P. Bejarano, J.M. Castilla, and M.A. Ramos, 2019
The glass transition phenomenon is a complex combination of kinetics and thermodynamics. Thus, experimentally the glass transition signals a crossover in the averaged molecular relaxation time from the short values of the liquid state to the long values identifying the solid state. The glass transition roughly occurs when the relaxation time is of the order of one hundred seconds. From the thermodynamic point of view, the glass transition looks like a second-order transition, with finite discontinuities in second derivatives of the Gibbs free energy, such as the specific heat. In contrast to the divergence of the melting of a crystal, glass transitions can be observed typically as a finite jump in $C_{p}$ curves, sometimes with an overshoot depending on the employed heating rate, associated to an enthalpy release [3,5].

However, there are several unsolved problems related to this phase transition: For instance, if one cools the liquid at a slower rate, the deviation from the equilibrium curve occurs at a lower $T_{g}$. This is a serious problem to consider it a proper phase transition temperature. Even worse, since the glass is in a non-equilibrium state, it exhibits time-dependent relaxation. So, by isothermal annealing of a glass below $T_{g}$ (or simply by aging at room temperature in many 


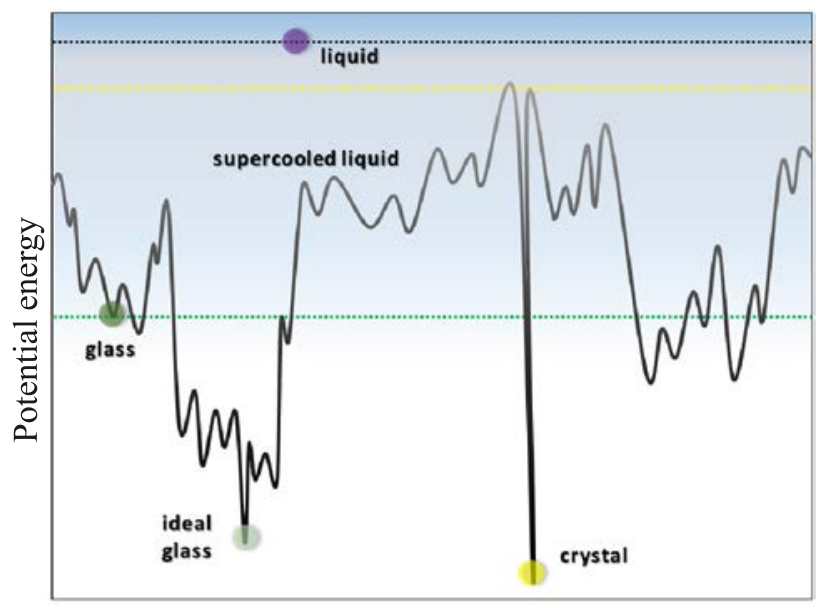

Generalized coordinates

Fig. 1. Potential energy landscape schematic picture, useful to describe the different condensed matter states (see text for details).

cases), the thermodynamic magnitudes can be relaxed to lower, more stable values.

We will not mention here the many different theories existing about the glass transition [8,9], but only remind the paradigm of the energy landscape [10] which is widely used [6-9]. The potential-energy landscape is essentially a topographic view of the $(3 N+1)$ potential-energy hypersurface of any glass-forming substance, as depicted in Fig. 1. As can be seen there, equilibrium states for the liquid are above the rugged energy landscape. Then, when the liquid is supercooled, the substance either crystalizes or bypasses the crystallization down to $T_{g}$, where it becomes a glass getting trapped in one of the many possible local minima or metastable states, depending on the thermal history followed. Interestingly, many authors have postulated the existence of an "ideal glass" [7-9] which should correspond to the best and most stable possible glass achievable, associated with the lowest relative minimum, though still above the energy of the crystalline absolute minimum.

\subsection{The entropy of glasses}

One of the most interesting open question concerning the thermodynamics of the glass transition is the so-called Kauzmann paradox [11] or entropy crisis. Let us consider the excess entropy $\Delta S(T)$ of a glass defined as the entropy of the supercooled liquid/glass minus the entropy of the crystal at any given temperature, which can be obtained by numerical integration from the corresponding crystal and glass specific heat $C_{p}(T)$ curves:

$$
\Delta S(T)=\Delta S_{m}-\int_{T}^{T_{L}} \frac{\left(C_{p, \text { glass }}-C_{p, \text { crystal }}\right)}{T^{\prime}} d T^{\prime},
$$

where $\Delta S_{m}$ is the entropy change at the melting temperature $T_{m}$.
Since the specific heat of the supercooled liquid is always larger than that of the crystal, the entropy reduction of the former is faster. By extrapolating available $\Delta S(T)$ curves, Kauzmann found [11] that the excess entropy decreases in many cases so quickly that it falls abruptly towards zero and eventually negative values at a finite temperature (the now called Kauzmann temperature $T_{K}$ ), what is against the thermodynamics laws! This is called a "thermodynamic catastrophe" or entropy crisis. In practice, the glass transition intervenes, and $\Delta S(T)$ does not vanish. The paradox is that a kinetic phenomenon (the increase in viscosity to leave ergodicity) avoids a thermodynamic crisis. Why does this occur? Any acceptable theory of the glass transition should explain this central issue. The thermodynamic viewpoint that emerges from this analysis considers the laboratory glass transition as a kinetically controlled manifestation of an underlying thermodynamic transition to an ideal glass with a unique configuration.

A second thermodynamic controversial point is the entropy of glasses in the limit of zero temperature. At the glass transition, the configurational entropy of the liquid is frozen-in, and thus the total entropy of the glass does not tend to zero as the entropy of the crystal does. In fact, the excess entropy usually decreases slightly with decreasing temperature for the vibrational entropy of the glass is not exactly the same as that of the crystal. Therefore, glasses seem not to hold the Third Law of Thermodynamics. This is usually interpreted [12-15] as they are in a nonequilibrium state with more than one available configuration even at $0 \mathrm{~K}$. Only pure crystalline states in thermodynamic equilibrium would follow the Third Law. Nonetheless, this is a controversial matter and a few groups claim that also glasses should have zero entropy in the limit of zero temperature [16,17]. The residual entropy $S_{\text {res }}=\Delta S(0)$ of the glass at zero Kelvin can be calculated through Eq. (1) by measuring the crystal $C_{p}(T)$ curve with a wellestablished zero entropy at $0 \mathrm{~K}$ up to the liquid state at a given reference temperature $T_{L}$, including the enthalpy of melting $\Delta H_{m}=T_{m} \Delta S_{m}$, and then integrating $C_{p} / T$ for the liquid/glass curve from that temperature $T_{L}$ down to zero.

In year 2000 Johari [18] collected available results on more than 30 glass-forming liquids. In Table I of that paper their residual entropies were shown (typically around $10 \mathrm{~J} /(\mathrm{K} \cdot \mathrm{mol}))$. For our case of interest, toluene, he obtained from the published results $S_{\text {res }}=7.9 \mathrm{~J} /(\mathrm{K} \cdot \mathrm{mol})$.

\subsection{Low-temperature anomalous properties of glasses}

Almost 50 years ago, Zeller and Pohl [19] demonstrated that low-temperature thermal properties of glasses did not follow at all the expected Debye behavior as non-metallic crystals do. In all studied substances, the specific heat of the glass below $\sim 1 \mathrm{~K}$ was found to be a few orders of magnitude larger than that of its crystalline counterpart, with a linear dependence on $T$ instead of the cubic dependence observed in crystals and well explained by Debye theory. 
Above $1-2 \mathrm{~K}$, a broad maximum in $C_{p} / T^{3}$ usually known as the "boson peak" is ubiquitously observed at around 4-10 $\mathrm{K}$ in glasses [20], that is indicative of a deviation from the expected horizontal behavior of the crystal at low enough temperatures. Indeed, a corresponding broad peak is also systematically observed by Raman-scattering or inelastic-neutron-scattering vibrational spectra [21,22], that is related to an excess in the reduced vibrational density of states (VDoS) over the frequency-squared Debye prediction for acoustic phonons, $g(\omega) / \omega^{2}$.

Also the thermal conductivity $\kappa(T)$ looks very different in crystals and glasses. Instead of the cubic increase with $T$ followed by a decrease due to phonon-phonon interactions typical of crystals, the thermal conductivity of the glass is orders of magnitude lower and increases as $T^{2}$, followed by a plateau, and then a further slow increase, in clear contrast to the crystal.

Very soon after the abovementioned work by Zeller and Pohl, two groups independently proposed the so-called Tunneling Model (TM) [23,24] to successfully explain many low-temperature "anomalous” properties below 1-2 K, including $C_{p}(T) \propto T, \kappa(T) \propto T^{2}$, as well as acoustic and dielectric properties [20]. Essentially, the TM postulated a simple, random distribution of asymmetric double-well potentials in amorphous solids arising from its configurational disorder. Hence additional low-energy excitations (tunneling two-level systems, TLS) appear in non-crystalline solids, ascribed to groups of atoms performing quantum tunneling motion between two configurations of similar potential energy, what accounts for that distinct behavior.

The situation above $1 \mathrm{~K}$ (that is, the boson peak, the plateau in thermal conductivity, etc.) is much more debated in the literature, with very different competing models and approaches. For instance, Schirmacher has proposed [25] a fluctuating elasticity theory (FET) that assumes a random distribution of elastic constants to explain the transformation of the typical Debye lattice dynamics into a VDoS producing a boson peak. On the other hand, Chumakov and coworkers have recently claimed [26] that the boson peak is nothing else that the occurrence in glasses of a smeared van Hove singularity for transverse phonon-like vibrations. Lubchenko and Wolynes [27] have associated the presence of TLS and the boson peak to cooperative motions within their Random First Order Theory of the glass transition.

Nevertheless, one of the approaches more often used to account for experimental data of glasses at low temperatures is provided by the Soft-Potential Model (SPM) and its extensions [28-31]. The SPM postulates the coexistence of acoustic phonons with quasilocalized vibrations or "soft modes". These are originated by a random distribution of quartic atomic potentials in glasses, which produces quasilocal configurations ranging from double-well potentials (hence including the TLS of the TM) to single, more or less harmonic, potentials that result into the boson peak in the
VDoS. We will assess our $C_{p}$ data at low temperatures quantitatively by recourse to the SPM (see Eq. (2) below).

\subsection{Toluene}

Toluene (also called methylbenzene) is a simple organic substance, its molecule comprising a benzene ring with one methyl group. Why is interesting to study toluene? First, it seems useful to explore in more detail its specific-heat behavior at lower temperatures, since it is a very fragile (bad) glass-forming liquid, and these often exhibit particular behavior compared to typical glasses. Furthermore, it is worth checking the suggestion by Leggett and Vural [32] that toluene glass could be a good benchmark of the TM, after single-molecule spectroscopy experiments conducted by Naimov et al. [33]. This technique is a powerful optical method for a direct observation of dynamical processes at low temperature, where the fluorescence of single chromophore molecules embedded in the sample gives information about the matrix dynamics in their local environment. These authors found [33] that the dynamics of several low-molecular-weight glasses as toluene, in contrast to standard glasses or polymers, did not follow the low-temperature behavior expected from TLS within the tunneling model.

In this paper, we present new measurements of the specific heat of toluene, both in its crystal and glass states, improving and extending earlier ones [34]. In the temperature range roughly between 1.8 and $22 \mathrm{~K}$, the standard thermal relaxation method was employed. In addition, a quasiadiabatic continuous method was used to cover the range up to the liquid state. From the whole of our measurements, complemented when needed with literature data, we have been able to obtain the entropy curves for the crystal and the glass states of toluene.

\section{Experimental}

\subsection{Materials and experimental techniques}

Toluene $\left(\mathrm{C}_{6} \mathrm{H}_{5} \mathrm{CH}_{3}\right)$ was purchased from SigmaAldrich (purity: > 99.9\%) and used without further purification. In order to be able to vitrify liquid toluene and avoid very rapid crystallization, toluene was doped with $2 \mathrm{~mol} \%$ ethanol, employing pure and dried ethanol (max. $0.02 \% \mathrm{H}_{2} \mathrm{O}$ ) also without further purification. In such a way, the specific heat curves for both glass and crystal states of the very same sample of toluene were measured and directly compared, in contrast to our previous measurements [34]. The small, additive known contribution of ethanol specific heat [35] to the measured heat capacity at low temperatures was correspondingly subtracted for glass and crystal. In addition, doping toluene with only $1 \mathrm{~mol} \%$ ethanol was tried too. However, crystallization always occurs in that case even quenching the liquid at $-50 \mathrm{~K} / \mathrm{min}$.

The heat capacity was measured using a versatile calorimetric set-up developed in our laboratory [36,37] espe- 
cially intended for glass-forming liquids. This calorimetric system allows to monitor and characterize the phase transitions in the range $77-300 \mathrm{~K}$, and then to measure their specific heat at lower temperatures by replacing the liquid nitrogen bath by liquid helium, eventually pumped to achieve temperatures of about $1.8 \mathrm{~K}$.

At temperatures below $25 \mathrm{~K}$, the well-known thermal relaxation method was employed, whereas at higher temperatures a quasiadiabatic continuous method was used [34,36,37]. Much more information about the cryogenic system employed, electronic control, thermal sensors and heating elements can be found in Ref. 37. Finally, in order to correctly subtract the contribution of the addenda to obtain the net specific heat of the toluene sample, the same calorimetric cell was also measured once emptied.

\subsection{Experimental results}

As discussed in our previous paper [34], earlier data of the specific heat of toluene are available for the crystal above $11 \mathrm{~K}$ [38] and for the glass above $5.6 \mathrm{~K}$ [39], using adiabatic calorimetry. Since toluene is a bad glass former and crystallizes readily, Yamamuro et al. [39] doped toluene with $10 \mathrm{~mol} \%$ benzene, then correcting the effects of doping by assuming the additivity of the heat capacities of toluene and benzene. We have been able to reduce significantly the amount of impurity by employing ethanol, whose more different molecular shape was expected to hinder crystallization more efficiently.

In Fig. 2, we show our new measurements of the specific heat of toluene doped with 2 mol\% ethanol, for the crystal state and for two differently prepared glasses, using the

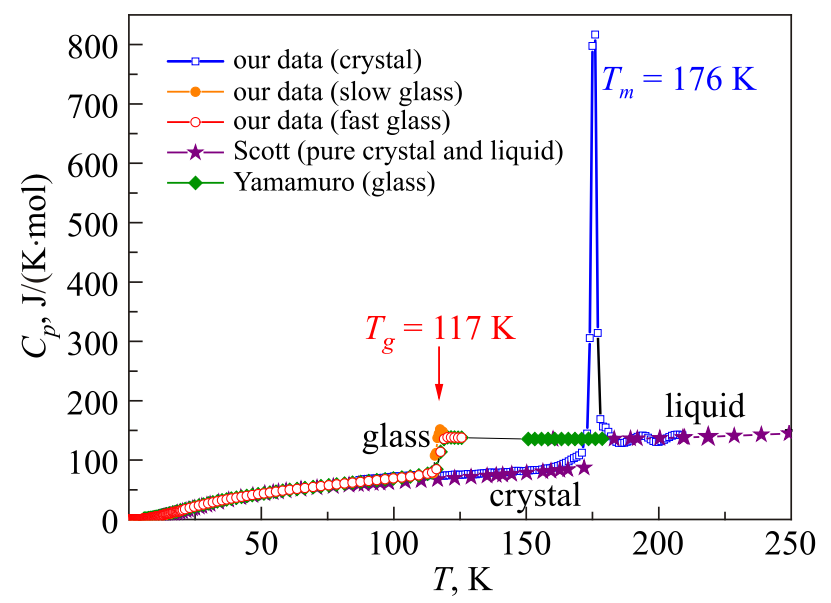

Fig. 2. (Color online) Specific heat in the whole measured range for the crystal (open squares) and two glasses (one slowly cooled, solid circles; one fast cooled, open circles; see text for details) of toluene doped with 2 mol\% ethanol. Glass transition is observed at $T_{g}=117 \mathrm{~K}$ and crystal melting at $T_{m}=176 \mathrm{~K}$. Earlier published data for the pure crystal and liquid [24] (solid stars) and the glass [25] (solid lozenges) are also shown for comparison. abovementioned quasiadiabatic continuous method. After measuring the $C_{p}$ curve of the crystal up to above its melting temperature $T_{m}=176 \mathrm{~K}$ (i.e., $(2 \pm 1) \mathrm{K}$ below that of pure toluene $[34,38]$ ), the liquid was quenched at about $-43 \mathrm{~K} / \mathrm{min}$ to bypass crystallization (fast glass). After measuring its $C_{p}(T)$ both at low and intermediate temperatures until slightly above the glass-transition temperature $T_{g}=117 \mathrm{~K}$, this supercooled liquid was frozen-in at a cooling rate of $-0.4 \mathrm{~K} / \mathrm{min}$ aiming to seek any possible difference between the properties of this slow glass and the former fast glass.

The specific heat of the crystal and of the two different glasses of toluene are plotted in Fig. 3 in a Debye-reduced $C_{p} / T^{3}$ vs $T$ representation, after subtraction of the addenda and correction for the ethanol contribution. Earlier published data at not very low temperatures for the pure crystal [38] and the glass [39] (after subtraction of $10 \mathrm{~mol} \%$ benzene) are also shown for comparison.

Both glasses are found to possess the same lowtemperature specific heat within experimental error, despite two orders of magnitude different cooling rates. A typical "boson peak" of glasses is observed at $4.5 \mathrm{~K}$, in agreement with our previous report for another toluene glass [34], and consistent with boson peak values in $g(\omega) / \omega^{2}$ reported by nuclear inelastic scattering [40] and by inelastic neutron scattering [41]. Moreover, previous measurements in the crystal down to $4.2 \mathrm{~K}$ were extended now accurately to $1.8 \mathrm{~K}$, allowing the true low-temperature Debye limit be reached. The correspondingly obtained Debye levels (see Fig. 4 and Discussion) are depicted by dashed lines.

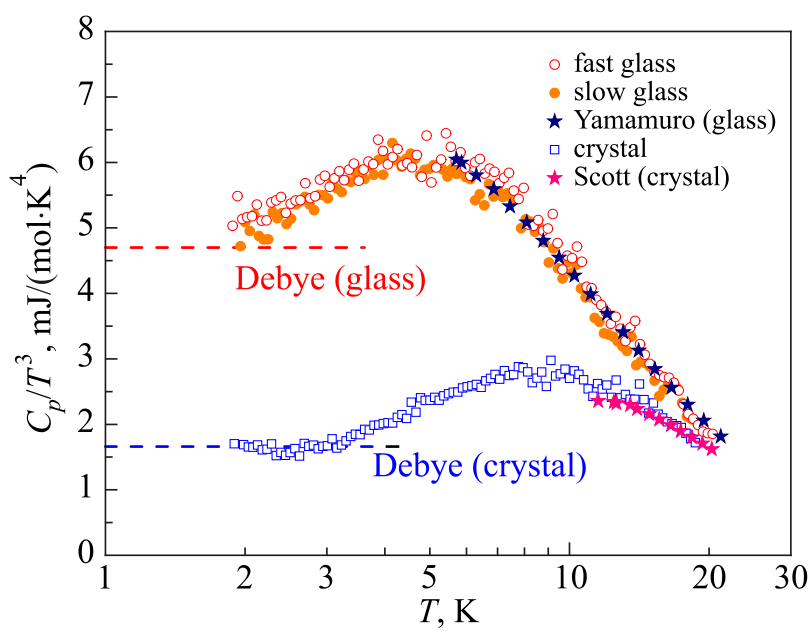

Fig. 3. (Color online) Debye-reduced $C_{p} / T^{3}$ data for both glasses (open and solid circles, for fast and slowly prepared glasses) and crystal (open squares) of toluene, after corrections of the $2 \mathrm{~mol} \%$ ethanol contribution. The estimated Debye levels (obtained by fitting data below $3.5 \mathrm{~K}$, see Fig. 4) for the glass and for the crystal are respectively indicated. Earlier data at not very low temperatures for the pure crystal [38] and the glass [39] (after subtraction of $10 \mathrm{~mol} \%$ benzene) are also shown for comparison. 


\section{Discussion}

In Fig. 4, the same specific-heat data presented in Fig. 3 but limited to below $4.5 \mathrm{~K}$ - are plotted as $C_{p} / T$ versus $T^{2}$. To evaluate the data, we have a conducted a simple Debye analysis for the crystal and a SPM fit for the two glasses considering both datasets together since they are indistinguishable. In the case of the crystal, a least-squares linear fit provides the Debye coefficient for the crystal $C_{D}=$ $=(1.66 \pm 0.04) \mathrm{mJ} /\left(\mathrm{mol} \cdot \mathrm{K}^{4}\right)$, and hence a molecular Debye temperature of $\Theta_{D}=105 \mathrm{~K}$. The obtained coefficient is clearly lower (and the corresponding $\Theta_{D}$ is higher) than the one that we reported previously [34]. However, in our previous work, data for the crystal below $4.5 \mathrm{~K}$ were scarce and not very accurate, hence hindering a proper determination of the Debye limit. On the contrary, in the present work we have reached $1.8 \mathrm{~K}$ and the horizontal Debye limit in $C_{p} / T^{3}$ for the toluene crystal is clearly observed, making the obtained values much more reliable.

Within a practical version of the SPM [42], at temperatures below the broad maximum in $C_{p} / T^{3}$ the specific heat of glasses follows the equation

$$
C_{p}=C_{T L S} T+C_{D} T^{3}+C_{s m} T^{5},
$$

where $C_{T L S}$ is the linear coefficient ascribed to the TLS as in the tunneling model, $C_{D}$ is just the elastic Debye coefficient due to lattice vibrations, and $C_{s m}$ is the contribution of the soft modes in the low-energy tail of the boson peak. In such a way, a simple quadratic fit below $3.5 \mathrm{~K}$ of toluene glass data in this $C_{p} / T$ vs $T^{2}$ representation directly provides the three coefficients of Eq. (2): $C_{T L S}=$

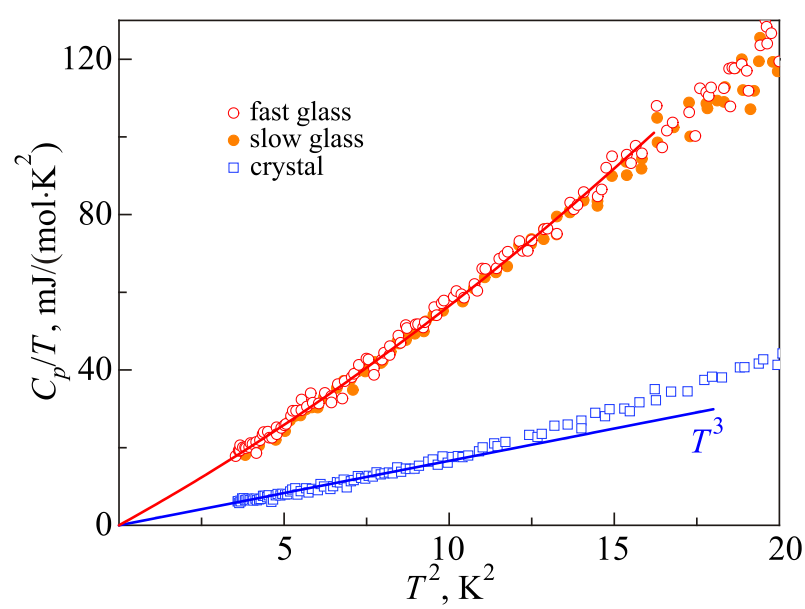

Fig. 4. (Color online) Specific heat of crystalline toluene (open squares) and of both fast and slow glasses (open and solid circles, respectively) at low temperatures, below about $4.5 \mathrm{~K}$. A leastsquares linear Debye fit of the data below $3 \mathrm{~K}$ for the crystal provides the Debye coefficient $\propto T^{3}$, shown by the blue solid line. A single fit following the soft-potential model has been applied to the two glass curves and is depicted by a red solid line, see text for details.
$=(0 \pm 1.5) \mathrm{mJ} /\left(\mathrm{mol} \cdot \mathrm{K}^{2}\right), C_{D}=(4.7 \pm 0.5) \mathrm{mJ} /\left(\mathrm{mol} \cdot \mathrm{K}^{4}\right)$, and $C_{s m}=(0.095 \pm 0.04) \mathrm{mJ} /\left(\mathrm{mol} \cdot \mathrm{K}^{6}\right)$. Thus, the Debye coefficient of the glass is higher than that of the crystal, and then its Debye temperature is lower, as expected, $\Theta_{D}=74.5 \mathrm{~K}$. Indeed, by simple inspection of Figs. 3 and 4 , it is clear that the specific heat of the glass state of toluene, in general, and the elastic Debye contribution, in particular, are much larger than those of its crystalline counterpart.

Nevertheless, the most striking finding is that the linear coefficient $C_{T L S}$ for toluene glass (graphically, the intercept with the ordinate axis in Fig. 4) is zero within experimental error, as for the crystal, confirming our previous measurements [34]. Therefore, we have identified a structural glass (amorphous solid) with a rather typical glassy boson peak but without TLS (or with a negligible amount of them), what is rather exceptional. This finding seems to be aligned with the abovementioned unusual behavior of toluene glass in the single-molecule spectroscopy experiments reported by Naimov et al. [33].

Finally, entropy curves (Fig. 5) have been obtained from our specific-heat data, complemented with earlier literature data when necessary, for the crystal (lower blue line), as well as for both the fast glass (open circles) and the slow glass (upper orange line), almost indistinguishable between them, and including the liquid above the melting point $T_{m}$. The inset zooms the curves at the lowest temperatures, showing the residual entropy of the glasses in the $0 \mathrm{~K}$ limit, $S_{\text {res }} \approx 5.1 \mathrm{~J} /(\mathrm{K} \cdot \mathrm{mol})$. This value is clearly lower that reported by Johari [18], $S_{\text {res }}=7.9 \mathrm{~J} /(\mathrm{K} \cdot \mathrm{mol})$. We believe that many of those residual entropy data found in the literature contain overestimations because they usually lack measurements of $C_{p}$ data of the corresponding glass state down to very low temperatures. They often performed Debye extrapolations to zero, missing the noticeable boson peak

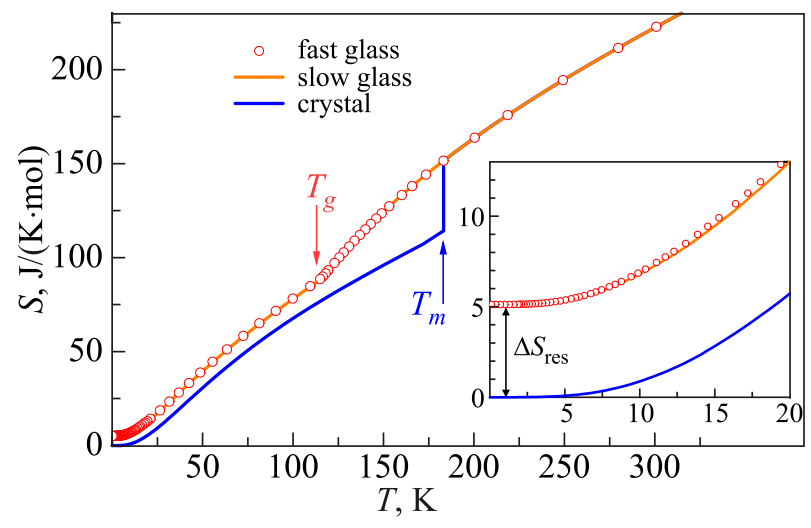

Fig. 5. (Color online) Entropy curves obtained from specific-heat data for the crystal (lower blue line) and for the fast glass (open circles) and the slow glass (orange curve), including the liquid above the melting point $T_{m}$. The inset zooms the curves at the lowest temperatures, showing the residual entropy of the glasses in the $0 \mathrm{~K}$ limit, $\Delta S_{\text {res }} \approx 5.1 \mathrm{~J} /(\mathrm{K} \cdot \mathrm{mol})$. 
and TLS contributions to $C_{p}$, hence reducing the integrand $C_{p \text {,glass }} / T$ to be subtracted in Eq. (1).

Interestingly, the value found for the residual entropy of toluene glass, $S_{\text {res }} \approx 5.1 \mathrm{~J} /(\mathrm{K} \cdot \mathrm{mol})=0.61 R$, is very close to $R \ln 2$. Thus, following Boltzmann equation for entropy, we may speculate that we have two microstates or configurations available per molecule, that is, one degree of freedom per molecule in average, as origin of the excess entropy of this glass.

\section{Summary and conclusions}

In summary, we have presented new measurements of the specific heat of toluene (doped with $2 \mathrm{~mol} \%$ ethanol to be able to access either crystallization or vitrification) in a wide temperature range down to $1.8 \mathrm{~K}$, for the very same sample in crystal state, in a glass state after fast cooling of the liquid and in another glass state after slow cooling. Differences between the two differently prepared glasses were negligible despite more than two orders of magnitude in their cooling rates.

We have shown that the crystal exhibits the expected Debye behavior below $4 \mathrm{~K}$, with a "molecular" Debye temperature of $\Theta_{D}=105 \mathrm{~K}$. The glass of toluene presents a pronounced boson peak at $T \approx 4.5 \mathrm{~K}$, typical of glasses. Nonetheless, the linear coefficient of the specific heat of the glass was found to be zero within experimental error, casting doubts about the complete universality of the lowtemperature anomalous properties of glasses. Complementary measurements (e.g., thermal conductivity) or specificheat measurements at even lower temperatures would be most interesting to confirm the reported absence of the ubiquitous TLS in glasses.

From the obtained $C_{p}$ curves for crystal and glass states, the entropy of the crystal and, more interestingly, the entropy of the glass (which needs the reference of the former to establish the zero value from the Third Law) have been determined. The residual entropy of the toluene glass in the 0 $\mathrm{K}$ limit was found to be $S_{\mathrm{res}} \approx 5.1 \mathrm{~J} /(\mathrm{K} \cdot \mathrm{mol})$, significantly lower than previously reported values which lacked reliable $C_{p}$ data of the glass at very low temperatures. The residual entropy of this bad glass former is then approximately $R \cdot \ln 2$, what may be interpreted as this glass retaining one degree of freedom per molecule of toluene in average.

\section{Acknowledgments}

Encouraging discussions with A.J. Leggett are gratefully acknowledged. This work has been partially supported by the Spanish Ministry of Economy through project FIS2017-84330-R, as well as by the Autonomous Community of Madrid through programme NANOFRONTMAGCM (S2013/MIT-2850).

1. P.W. Anderson, Science 267, 1615 (1995).

2. R. Zallen, The Physics of Amorphous Solids, Wiley (1983).
3. S.A. Brawer, Relaxation in Viscous Liquids and Glasses, Am. Ceram. Soc. (1983).

4. S.R. Elliott, Physics of Amorphous Materials, 2nd ed., Longman (1990).

5. I. Gutzow and J.W.P. Schmelzer, The Vitreous State, Springer (1995).

6. F.H. Stillinger, Science 267, 1935 (1995).

7. P.G. Debenedetti and F.H. Stillinger, Nature 410, 259 (2001).

8. K. Binder and W. Kob, Glassy Materials and Disordered Solids, World Scientific (2005).

9. A. Cavagna, Phys. Rep. 476, 51 (2009).

10. M. Goldstein, J. Chem. Phys. 51, 3728 (1969).

11. W. Kauzmann, Chem. Rev. 43, 219 (1948).

12. S.A. Langer and J.P. Sethna, Phys. Rev. Lett. 61, 570 (1988).

13. M. Goldstein, J. Chem. Phys. 128, 154510 (2008).

14. I. Gutzow and J.W.P. Schmelzer, J. Non-Cryst. Solids 355, 581 (2009).

15. A. Takada, R. Conradt, and P. Richet, J. Non-Cryst. Solids 429, 33 (2015).

16. P.K. Gupta and J.C. Mauro, J. Non-Cryst. Solids 355, 595 (2009).

17. J.C. Mauro, R.J. Loucks, S. Sen, and J. Chem. Phys. 133, 164503 (2010).

18. G.P. Johari, J. Chem. Phys. 112, 8958 (2000).

19. R.C. Zeller and R.O. Pohl, Phys. Rev. B 4, 2029 (1971).

20. Amorphous Solids: Low-Temperature Properties, W.A. Phillips (ed.), Springer (1981).

21. U. Buchenau, M. Prager, N. Nücker, A.J. Dianoux, N. Ahmad, and W.A. Phillips, Phys. Rev. B 34, 5665 (1986).

22. V.K. Malinovsky, V.N. Novikov, P.P. Parshin, A.P. Sokolov, and M.G. Zemlyanov, Europhys. Lett. 11, 43 (1990).

23. W.A. Phillips, J. Low Temp. Phys. 7, 351 (1972).

24. P.W. Anderson, B.I. Halperin, and C.M. Varma, Philos. Mag. 25, 1 (1972).

25. W. Schirmacher, Europhys. Lett. 73, 892 (2006).

26. A.I. Chumakov, G. Monaco, A. Fontana, A. Bosak, R.P. Hermann, D. Bessas, B. Wehinger, W.A. Crichton, M. Krisch, R. Rüffer, G. Baldi, G. Carini, Jr, G. Carini, G. D'Angelo, E. Gilioli, G. Tripodo, M. Zanatta, B. Winkler, V. Milman, K. Refson, M.T. Dove, N. Dubrovinskaia, L. Dubrovinsky, R. Keding, and Y.Z. Yue, Phys. Rev. Lett. 112, 025502 (2014).

27. V. Lubchenko and P.G. Wolynes, Annu. Rev. Phys. Chem. 58, 235 (2007).

28. U. Buchenau, Yu.M. Galperin, V.L. Gurevich, D.A. Parshin, M.A. Ramos, and H.R. Schober, Phys. Rev. B 46, 2798 (1992).

29. L. Gil, M.A. Ramos, A. Bringer, and U. Buchenau, Phys. Rev. Lett. 70, 182 (1993).

30. For a review, see D.A. Parshin, Phys. Rev. B 49, 9400 (1994); M.A. Ramos and U. Buchenau, in Tunneling Systems in Amorphous and Crystalline Solids, P. Esquinazi (ed.) Springer (1998), Chap. 9.

31. V.L. Gurevich, D.A. Parshin, and H.R. Schober, Phys. Rev. B 67, 094203 (2003). 
32. A.J. Leggett and D.C. Vural, J. Phys. Chem. B 117, 12966 (2013)

33. I.Y. Eremchev, Y.G. Vainer, A.V. Naumov, and L. Kador, Phys. Chem. Chem. Phys. 13, 1843 (2011).

34. C. Alvarez-Ney, J. Labarga, M. Moratalla, J.M. Castilla, and M.A. Ramos, J. Low Temp. Phys. 187, 182 (2017).

35. C. Talón, M.A. Ramos, and S. Vieira, Phys. Rev. B 66, 012201 (2002).

36. E. Pérez-Enciso and M.A. Ramos, Termochimica Acta 461, 50 (2007).

37. T. Pérez-Castañeda, J. Azpeitia, J. Hanko, A. Fente, H. Suderow, and M.A. Ramos, J. Low Temp. Phys. 173, 4 (2013).

38. D.W. Scott, G.B. Guthrie, J.F. Messerly, S.S. Todd, W.T. Berg, I.A. Hossenlopp, and J.P. McCullough, J. Phys. Chem. 66, 911 (1962).

39. O. Yamamuro, I. Tsukushi, A. Lindqvist, S. Takahara, M. Ishikawa, and T. Matsuo, J. Phys. Chem. B 102, 1605 (1998).

40. A.I. Chumakov, I. Sergueev, U. van Bürck, W. Schirmacher, T. Asthalter, R. Rüffer, O. Leupold, and W. Petry, Phys. Rev. Lett. 92, 245508 (2004).

41. I. Tsukushi, O. Yamamuro, K. Yamamoto, K. Takeda, T. Kanaya, and T. Matsuo, J. Phys. Chem. Solids 60, 1541 (1999).

42. M.A. Ramos, Philos. Mag. 84, 1313 (2004).

\section{Залишкова ентропія толуолу в скляному стані в наближенні нульової температури}

\section{Moratalla, P. Bejarano, J.M. Castilla, M.A. Ramos}

3 особливою точністю методом термічної релаксації в температурному інтервалі 1,8-20 К досліджено питому теплоємність $C_{p}$ толуолу, допованого етанолом (2 моль\% для запобігання швидкої кристалізації) як в скляному, так i в кристалічому станах. 3 використанням додаткових кривих $C_{p}$, які виміряно для еталонного кристалічного стану, отримано ентропійну криву та в наближенні нульової температури оцінено залишкову ентропію толуолу в скляному стані, яка склала 5,1 Дж/(К·мол). Це значення істотно нижче, ніж наявні в літературі, в якій не міститься інформація про питому теплоємність стекол при низьких температурах, що призводить до переоцінки залишкової ентропії скла при нульовій температурі. Крім того, ми детально вивчили низькотемпера- турні «скляні аномалії» толуолу, розширюючи та покращуючи попередні вимірювання. Підтверджено існування раніше виявленої інверсної області, що обумовлена тунельними дворівневими системами в скляному стані толуолу, хоча ця аномалія співіснує $з$ широким піком, типовим для стекол (так званий бозонний пік), в $C_{p} / T^{3}$ при 4,5 К. Для кристалічного толуолу очікувану кубічну дебаєвську поведінку теплоємності виявлено при більш низьких температурах.

Ключові слова: питома теплоємність, скляний перехід, толуол, ентропія стекол, тунельні стани, бозонний пік.

\section{Остаточная энтропия толуола в стекольном состоянии в пределе нулевой температуры}

\section{Moratalla, P. Bejarano, J.M. Castilla, M.A. Ramos \\ С особой точностью методом термической релаксации в} температурном интервале 1,8-20 К исследована удельная теплоемкость $C_{p}$ толуола, допированного этанолом (2 моль\% для исключения быстрой кристаллизации) как в стекольном, так и в кристаллическом состояниях. Используя дополнительные кривые $C_{p}$, измеренные для эталонного кристаллического состояния, получена энтропийная кривая и в пределе нулевой температуры оценена остаточная энтропия толуола в стекольном состоянии, которая составила 5,1 Дж/(К·мол). Это значение существенно ниже, чем имеющиеся в литературе, не содержащей информации об удельной теплоемкости стекол при низких температурах, что приводит к переоценке остаточной энтропии стекла при нулевой температуре. Кроме того, мы подробно изучили низкотемпературные «стекольные аномалии» толуола, расширяя и улучшая предыдущие исследования. Подтверждено существование ранее обнаруженной инверсной области, обусловленной туннельными двухуровневыми системами в стекольном состоянии толуола, хотя эта аномалия сосуществует с широким пиком, типичным для стекол (так называемый бозонный пик), в $C_{p} / T^{3}$ при 4,5 К. Для кристаллического толуола ожидаемое кубическое дебаевское поведение теплоемкости обнаружено при более низких температурах.

Ключевые слова: удельная теплоемкость, стекольный переход, толуол, энтропия стекол, туннельные состояния, бозонный пик. 